\title{
Nonsteroidal Anti-inflammatory Drugs for Sciatica
}

\author{
An Updated Cochrane Review
}

\author{
Eva Rasmussen-Barr, $\mathrm{PhD},{ }^{*, \dagger}$ Ulrike Held, $\mathrm{PhD},{ }^{\ddagger}$ Wilhelmus J.A. Grooten, $\mathrm{PhD},{ }^{\dagger}$ \\ Pepijn D.D.M. Roelofs, PhD, ${ }^{\S}$ Bart W. Koes, PhD, "Maurits W. van Tulder, PhD," \\ Maria M. Wertli, MD, $\mathrm{PhD}^{\ddagger}$
}

\begin{abstract}
Study Design. Systematic review and meta-analysis.
Objective. To determine the efficacy of nonsteroidal anti-inflammatory drugs (NSAIDs) on pain reduction, overall improvement, and reported adverse effects in people with sciatica.
\end{abstract}

Summary of Background Data. NSAIDs are one of the most frequently prescribed drugs for sciatica.

Methods. We updated a 2008 Cochrane Review through June 2015. Randomized controlled trials that compared NSAIDs with placebo, with other NSAIDs, or with other medication were included. Outcomes included pain using mean difference (MD, $95 \%$ confidence intervals $[95 \% \mathrm{Cl}]$ ). For global improvement and adverse effects risk ratios $(\mathrm{RR}, 95 \% \mathrm{Cl})$ were used. We assessed level of evidence using the Grades of Recommendation, Assessment, Development and Evaluation approach.

Results. Ten trials were included $(\mathrm{N}=1651)$. Nine out of 10 trials were assessed at high risk of bias. For pain reduction (visual analog scale, 0 to 100) NSAIDs were no more effective than placebo (MD $-4.56,95 \% \mathrm{Cl}-11.11$ to 1.99 , quality of evidence: very low). For global improvement NSAIDs were more effective than placebo (RR $1.14[95 \% \mathrm{Cl} 1.03$ to 1.27$]$, low

From the *The Institute of Environmental Medicine, Department of Cardiovascular Epidemiology, Karolinska Institutet, Stockholm, Sweden; ${ }^{\dagger}$ Department of Neurobiology, Care Sciences and Society, Division of Physiotherapy, Karolinska Institutet, Huddinge, Sweden; ${ }^{\dagger}$ Horten Centre for Patient Oriented Research, University of Zurich, Zurich, Switzerland; ${ }^{\S}$ Research Centre Innovations in Care, Rotterdam University of Applied Sciences, Rotterdam, The Netherlands; "Department of General Practice, Erasmus Medical Center, Rotterdam, The Netherlands; and "Department of Health Sciences, Faculty of Earth and Life Sciences, VU University Amsterdam, Amsterdam, The Netherlands.

Acknowledgment date: January 3, 2017. Acceptance date: January 4, 2017.

This review is adapted from the Cochrane Review; "Rasmussen-Barr E, Held $\mathrm{U}$, Grooten, JWA, et al. Nonsteroidal anti-inflammatory drugs for sciatica. Cochrane Database Syst Rev 2016;(10):Art. no.: CD012382. doi: 10.1002/ $1465185^{\prime \prime}$. Copyright Cochrane Library, reproduced with permission.

The device(s)/drug(s) is/are FDA-approved or approved by corresponding national agency for this indication.

No funds were received in support of this work.

Relevant financial activities outside the submitted work: grants, travel/ accommodations/meeting expenses.

Address correspondence and reprint requests to Eva Rasmussen-Barr, PhD, The Institute of Environmental Medicine, Department of Cardiovascular Epidemiology, Karolinska Institutet, Box 210, SE-17177 Stockholm, Sweden; E-mail: eva.rasmussen.barr@ki.se

DOI: $10.1097 /$ BRS.0000000000002092 quality of evidence). One trial reported the effect of NSAIDs on disability with very low-quality evidence that NSAIDs are no more effective than placebo. There was low-quality evidence that the risk for adverse effects is higher for NSAID than placebo (RR $1.40,95 \%$ Cl 1.02 to 1.93 ).

Conclusion. Our findings show very low-quality evidence that the efficacy of NSAIDs for pain reduction is comparable with that of placebo, low-quality evidence that NSAIDs is better than placebo for global improvement and low-quality evidence for higher risk of adverse effects using NSAIDs compared with placebo. The findings must be interpreted with caution, due to small study samples, inconsistent results, and a high risk of bias in the included trials.

Key words: analgesics, Cochrane Review, low-back pain/drug therapy, medication, meta-analysis, nonsteroidal antiinflammatory drug/adverse effects, pain management, rehabilitation, sciatica/drug therapy, systematic review.

Level of Evidence: 1

Spine 2017;42:586-594

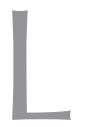

ow back pain (LBP) is one of the most common medical disorders in the world, ${ }^{1,2}$ affecting functional capacity and work absence and resulting in personal suffering and huge socioeconomic cost. ${ }^{1,3}$ Sciatica is an important subgroup of LBP. The prevalence of sciatica varies depending on the time period studied: lifetime prevalence is reported as between $12.2 \%$ and $43 \%$, period prevalence between $2.2 \%$ and $34 \%$, and point prevalence between $1.5 \%$ and $13.4 \% .^{4}$ The prognosis is considered to be worse and more disabling than common LBP. ${ }^{4-6}$ The clinical course of acute sciatica, however, is in general considered to be favorable, and most pain and disability resolve within a couple of weeks. ${ }^{6}$ The term "sciatica" describes a symptom and not a specific diagnosis. ${ }^{5-10}$ Clinical symptoms associated with sciatica are leg pain radiating below the knee and into the foot and toes, muscle weakness, sensory changes such as pins and needles or numbness following the dermal pattern, impaired reflexes, or the presence of a positive straight leg raising test. ${ }^{4-6,11}$

Medication plays an important role in the management of sciatica. NSAIDs are one of the most frequently prescribed 
pain drugs worldwide for treating sciatica ${ }^{12}$ Many different NSAIDs exist based on six major chemical structures that differ in their dose, drug interactions, and adverse effects. The main anti-inflammatory, antipyretic, and analgesic effect of NSAIDs is based on the suppression of the cyclooxygenase (COX)-1 and COX-2 enzymes. By blocking the COX enzymes, vasodilation is reduced and inflammation relieved. Furthermore, the synthesis of prostaglandins is blocked, leading to reduced pain. ${ }^{13,14}$ The NSAIDs block the prostaglandin synthesis similar to steroids but without adverse effects observed in steroids. However, NSAIDs are responsible for various adverse effects; gastrointestinal, cardiovascular, renal, and hepatotoxic adverse effects are described. ${ }^{15}$ The well-known gastrointestinal adverse effects of NSAIDs are caused by blocking of the COX-1 enzyme, which leads to a reduction in mucosal prostaglandin synthesis, and its protective effects. NSAIDs are therefore associated with an increased risk for early gastrointestinal complications.

NSAIDs are recommended in clinical guidelines for sciatica, ${ }^{6,12,16}$ but a previous Cochrane review ${ }^{12}$ showed limited evidence to support the efficacy of NSAIDs in sciatica. Our primary objective was to update a previous Cochrane review $^{12}$ to determine the efficacy of NSAIDs in pain reduction, overall improvement, and reported adverse effects in people with sciatica.

\section{MATERIAL AND METHODS}

\section{Types of studies}

We included randomized controlled trials (RCTs) (doubleblind, single-blind, and open-label). We used no language restriction. Trials included participants aged 16 years or older with acute, subacute, and chronic $(>12$ weeks) sciatica.

Sciatica was defined as pain radiating to one or both legs below the knee with some of the following signs; positive straight leg raising test, or Lasègue sign presenting with numbness, pins or needles in a dermatomal distribution; and muscle weakness or reflex changes or both in a myotome distribution. We excluded people with sciatica caused by specific pathological entities such as infection, neoplasm, metastasis, osteoporosis, rheumatoid arthritis, or fractures.

We included RCTs that investigated one or more types of NSAIDs. Additional interventions were allowed if there was a contrast for the treatment with NSAIDs in the trial. We considered the following comparator groups: (1) placebo, (2) other NSAIDs, and (3) other pharmacological agents, alone or in combination (e.g., corticosteroids, muscle relaxants, antidepressants). We excluded trials that compared NSAIDs in combination with other pharmacological agents or nonpharmacological treatments compared with another intervention and NSAIDs compared with nondrug treatments.

\section{Primary Outcomes}

Included trials reported on (1) change in pain intensity (e.g., visual analog scale [VAS] or numerical rating scale), (2) change in disability or functional status (e.g., Oswestry
Disability Questionnaire or Roland Morris Disability Questionnaire, and (3) global measures (e.g., overall improvement).

\section{Secondary Outcomes}

Secondary outcomes were reported adverse effects (proportions of participants experiencing adverse effects of NSAIDs) and the use of additional medication.

\section{Search Methods for Identification of Studies}

We searched Cochrane Central Register of Controlled Trials (CENTRAL, the Cochrane Library, Issue 5, 2015; includes the Cochrane Back and Neck [CBN] Review Group's Trials Register), MEDLINE, EMBASE, ClinicalTrials.gov, World Health Organization International Clinical Trials, Registry Platform (WHO ICTRP), and PubMed up until June 2015 for RCTs meeting the inclusion criteria. Additional trials were identified through examination of references from identified trials and systematic reviews. The complete search strategy is presented in Appendix 1, http://links.lww.com/ BRS/B256.

\section{Selection of Studies}

Several authors independently screened titles, abstracts, and keywords to identify trials that met the inclusion criteria. We obtained and screened full texts of trials if either the study seemed to meet the inclusion criteria or if inclusion was uncertain. Disagreements were solved by consensus of the review authors or third-party arbitration.

\section{Data Extraction and Management}

Three authors extracted the data from the trials on characteristics of participants, interventions, primary and secondary outcomes, adverse effects, and industry sponsorship of the trial. Three authors extracted the mean difference (MD) scores, standard deviations, and sample size using a data extraction form. All disagreements were resolved through discussion. In the case of potentially relevant missing information in the papers, we contacted the corresponding authors.

\section{Data Synthesis}

We analyzed dichotomous outcomes by calculating the risk ratio (RR) with $95 \%$ confidence intervals $(\mathrm{CI})$. We analyzed continuous outcomes by calculating the MD with $95 \%$ CI. We considered a $P$-value of less than 0.05 to be statistically significant. We pooled data if two or more studies investigated comparable outcome measures. For the metaanalyses (both the fixed- and the random-effects approach), we considered only studies that used medications currently on the market.

We assessed the quality of the evidence for all outcomes regardless of whether there were sufficient data available to use quantitative analyses to summarize the data. We rated the quality of the evidence according to the Grades of Recommendation, Assessment, Development and Evaluation (GRADE) approach, ${ }^{17}$ recommended in the 
Cochrane Handbook ${ }^{18}$ and adapted in the updated CBN guidelines. ${ }^{19}$ We graded trials on specific domains recommended by the Cochrane CBN tool: (1) risk of bias, (2) inconsistency, (3) indirectness, (4) imprecision, and (5) other factors (e.g., publication bias). ${ }^{19}$ We used the statistical software Review Manager (RevMan) Version 5.3 (The Nordic Cochrane Centre, The Cochrane Collaboration, Copenhagen).

\section{Risk of Bias}

Three review authors (E.R.B., M.W., W.G.) independently assessed the risk of bias of the included trials based on criteria described in the CBN's tool for assessing risk of bias. ${ }^{19}$ We defined high-quality studies as fulfilling six or more of the validity criteria. We assessed the following factors for other sources of potential bias: funding and other biases such as (low) sample size and how the data were presented. ${ }^{19}$ We did not downgrade the evidence when all trials were judged as low risk of bias for all five categories. We downgraded the evidence by one level when more than three categories had a high or unclear risk. We downgraded the evidence by two levels when four or more categories had a high or unclear risk.

\section{Inconsistency}

We downgraded the quality of evidence by one level when heterogeneity or variability in results was large $\left(I^{2}>80 \%\right)$ and two levels when there was in addition inconsistency arising from populations, interventions, or outcomes. ${ }^{17,19}$

\section{Indirectness}

We downgraded one level whether there was an uncertainty about generalizability of the results in one area (e.g., population, intervention, comparator, or outcome), and we downgraded two levels when there was indirectness in two or more areas. ${ }^{17,19}$

\section{Imprecision}

We downgraded by one level when trials included relatively few participants and few events or had wide confidence intervals around the estimate of the effect and when there was only one trial and when there was more than one trial and the total number of events was lower than 300 for dichotomous data and 400 for continuous data. ${ }^{17,19} \mathrm{We}$ downgraded two levels if there were both few events, few patients, and wide confidence intervals.

\section{Publication Bias}

The quality of evidence was downgraded by one level if the funnel plots suggested publication bias.

\section{RESULTS}

We identified 2629 references, obtained full-text articles for 37 references with $10 \mathrm{RCTs}^{20-28}$ (nine publications) meeting the inclusion criteria $(\mathrm{N}=1651)$ of which two trials ${ }^{27,28}$ were added compared with the original review ${ }^{29}$ (Figure 1, Appendix 2, http://links.lww.com/BRS/B257).

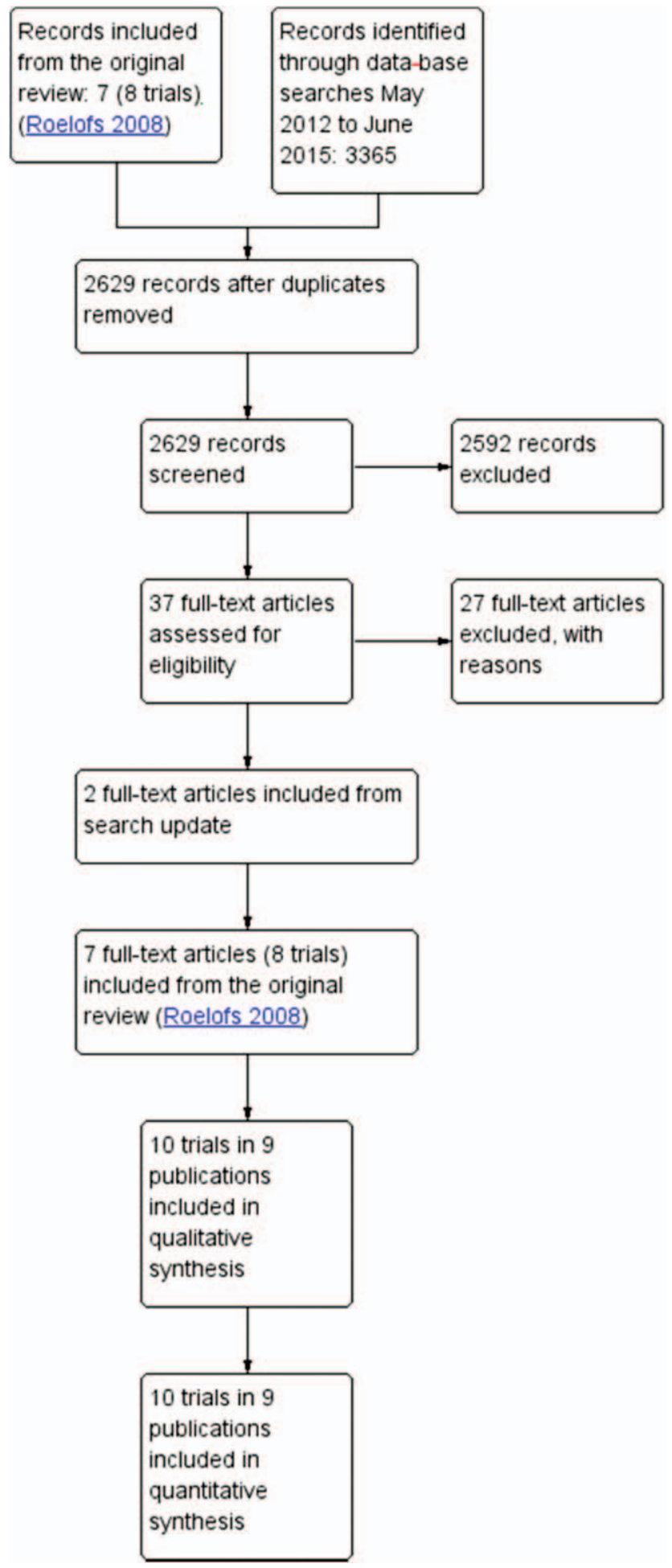

Figure 1. Study flow diagram.

\section{Included Studies}

Five trials used the currently recommended daily dose of NSAIDs, ${ }^{20,21,26,27}$ whereas two ${ }^{22,28}$ used lower doses (Table 1). Three trials investigated NSAIDs no longer approved for human use. ${ }^{23-25}$ Most trials included smaller samples $(n=25-59)$, whereas some ${ }^{21,26,27}$ included larger samples $(n=171-532)$. Most trials included participants seeking care for acute sciatica of less than 3 weeks' duration. 


\begin{tabular}{|c|c|c|c|c|c|c|}
\hline $\begin{array}{l}\text { ATC Group, } \\
\text { Trial }\end{array}$ & Substance & Daily Dose & $\begin{array}{l}\text { Recommended } \\
\text { Maximum Dose }\end{array}$ & $\begin{array}{l}\text { Treatment } \\
\text { Duration }\end{array}$ & $\begin{array}{l}\text { Sample Size } \\
\text { Calculation }\end{array}$ & $\begin{array}{l}\text { Participants Per } \\
\text { Group (n) }\end{array}$ \\
\hline \multicolumn{7}{|l|}{ Butylpyrazolidin } \\
\hline Grevsten 1975 & $\begin{array}{c}\text { Phenylbutazone } \\
\text { (Butazolidin) IM } \\
\text { day } 1 ; \\
\text { phenylbutazone } \\
\text { (Butazolidin } \\
\text { Alka) orally day } \\
2 \text { to } 4\end{array}$ & $\begin{array}{c}0.6 \mathrm{~g} \text { IM day } 1, \\
0.6 \mathrm{~g} \text { day } 2 \text { to } 4 \\
\text { by mouth, } 0.3 \mathrm{~g} \\
\text { day } 5 \text { to } 14\end{array}$ & $\begin{array}{l}\text { No longer } \\
\text { approved for } \\
\text { human use }\end{array}$ & 14 days & No & 36 \\
\hline Weber 1980 & $\begin{array}{c}\text { Phenylbutazone } \\
\text { (Butazolidin } \\
\text { Alka) }\end{array}$ & $\begin{array}{c}600 \mathrm{mg} \text { day } 1 \text { to } \\
3,300 \mathrm{mg} \text { day } 4 \\
\text { to } 5\end{array}$ & $\begin{array}{l}\text { No longer } \\
\text { approved for } \\
\text { human use }\end{array}$ & 5 days & No & 59 \\
\hline Radin 1968 & Phenylbutazone & $\begin{array}{c}600 \mathrm{mg} \text { day } 1 \text { to } \\
2,300 \text { to } 800 \mathrm{mg} \\
\text { day } 3 \text { to } 8\end{array}$ & $\begin{array}{l}\text { No longer } \\
\text { approved for } \\
\text { human use }\end{array}$ & 8 days & No & 25 \\
\hline \multicolumn{7}{|c|}{ Acetic acid derivatives } \\
\hline Goldie 1968 & Indomethacin & $75 \mathrm{mg}$ & $225 \mathrm{mg}$ & 14 days & No & 25 \\
\hline Herrmann 2009 & Diclofenac & $\begin{array}{l}100 \mathrm{mg} \text { day } 1 \\
\text { and } 5 ; 150 \mathrm{mg} \\
\text { day } 2 \text { to } 4\end{array}$ & 150 to $200 \mathrm{mg}$ & 4 days & 50 per group & 57 \\
\hline Dreiser 2001 & Diclofenac & $150 \mathrm{mg}$ & 150 to $200 \mathrm{mg}$ & 14 days & 150 per group & 162 \\
\hline Kanayama 2005 & $\begin{array}{c}\text { Diclofenac vs. } \\
\text { active } \\
\text { treatment }\end{array}$ & $75 \mathrm{mg}$ & 150 to $200 \mathrm{mg}$ & 14 days & 20 per group & 20 \\
\hline \multicolumn{7}{|c|}{ Oxicams } \\
\hline \begin{tabular}{l|} 
Dreiser 2001 \\
(placebo- \\
controlled trial)
\end{tabular} & $\begin{array}{c}\text { Meloxicam } \\
7.5 / 15 \mathrm{mg} \\
\end{array}$ & $7.5 / 15 \mathrm{mg}$ & $15 \mathrm{mg}$ & 7 days & 150 per group & $171 / 181$ \\
\hline $\begin{array}{l}\text { Dreiser } 2001 \\
\text { (diclofenac- } \\
\text { controlled trial) }\end{array}$ & $\begin{array}{l}\text { Meloxicam } \\
7.5 / 15 \mathrm{mg}\end{array}$ & $7.5 / 15 \mathrm{mg}$ & $15 \mathrm{mg}$ & 14 days & 150 per group & $164 / 163$ \\
\hline Weber 1993 & Piroxicam & $\begin{array}{l}100 \mathrm{mg} \text { day } 1 \text { to } \\
2,20 \mathrm{mg} \text { day } \\
3 \text { to } 14\end{array}$ & $20 \mathrm{mg}$ & 14 days & No & 120 \\
\hline Herrmann 2009 & Lornoxicam & $\begin{array}{l}24 \mathrm{mg} \text { day } 1 ; \\
16 \mathrm{mg} \text { day } 2 \\
\text { to } 4 ; 8 \mathrm{mg} \text { day } \\
5\end{array}$ & $16 \mathrm{mg}$ & 5 days & 50 per group & 57 \\
\hline \multicolumn{7}{|c|}{ Propionic acid derivative } \\
\hline Braun 1982 & $\begin{array}{l}\text { Ketoprofen } v s . \\
\text { active } \\
\text { treatment }\end{array}$ & $\begin{array}{c}200 \mathrm{mg} \text { IM day } 1 \\
\text { to } 3,300 \mathrm{mg} \\
\text { orally }+ \text { supp } \\
\text { day } 4 \text { to } 8\end{array}$ & $\begin{array}{l}200(\max 300) \\
\text { mg }\end{array}$ & 9 days & No & 17 \\
\hline \multicolumn{7}{|c|}{ Fenamates, coxibs, or others } \\
\hline No studies & - & - & - & - & - & - \\
\hline
\end{tabular}

The follow-up duration varied from 3 to 8 hours to 1 year. The trials were conducted in the USA, ${ }^{24}$ Japan, ${ }^{28}$ Germany, ${ }^{20,27}$ Sweden, ${ }^{22,23}$ and in Norway. ${ }^{25,26}$

\section{Description of Studies}

\section{NSAID Versus Placebo}

Four trials ${ }^{20,21,26,28}$ reported on pain relief (VAS 0 to 100), one $^{26}$ on functional outcome (Roland Morris Disability Questionnaire [RMDQ]) at 14 days and 4 weeks. Five trials $21,23,25-27$ reported on global improvement. Radin and Bryan ${ }^{24}$ did not report how global improvement was measured and was therefore not included. In all trials except one ${ }^{28}$ the use of additional medication was allowed: paracetamol with or without codeine, promethazine ${ }^{25}$ and levomepromazine. ${ }^{26}$

\section{NSAID Versus NSAID}

One trial ${ }^{27}$ compared lornoxicam with diclofenac, whereas one $^{21,27}$ compared meloxicam $(7.5 / 15 \mathrm{mg})$ with diclofenac (150 mg).

\section{NSAID Versus Other Drugs}

Braun and Huberty ${ }^{20}$ compared ketoprofen orally with a combination of steroids and phenylbutazone (intramuscular 


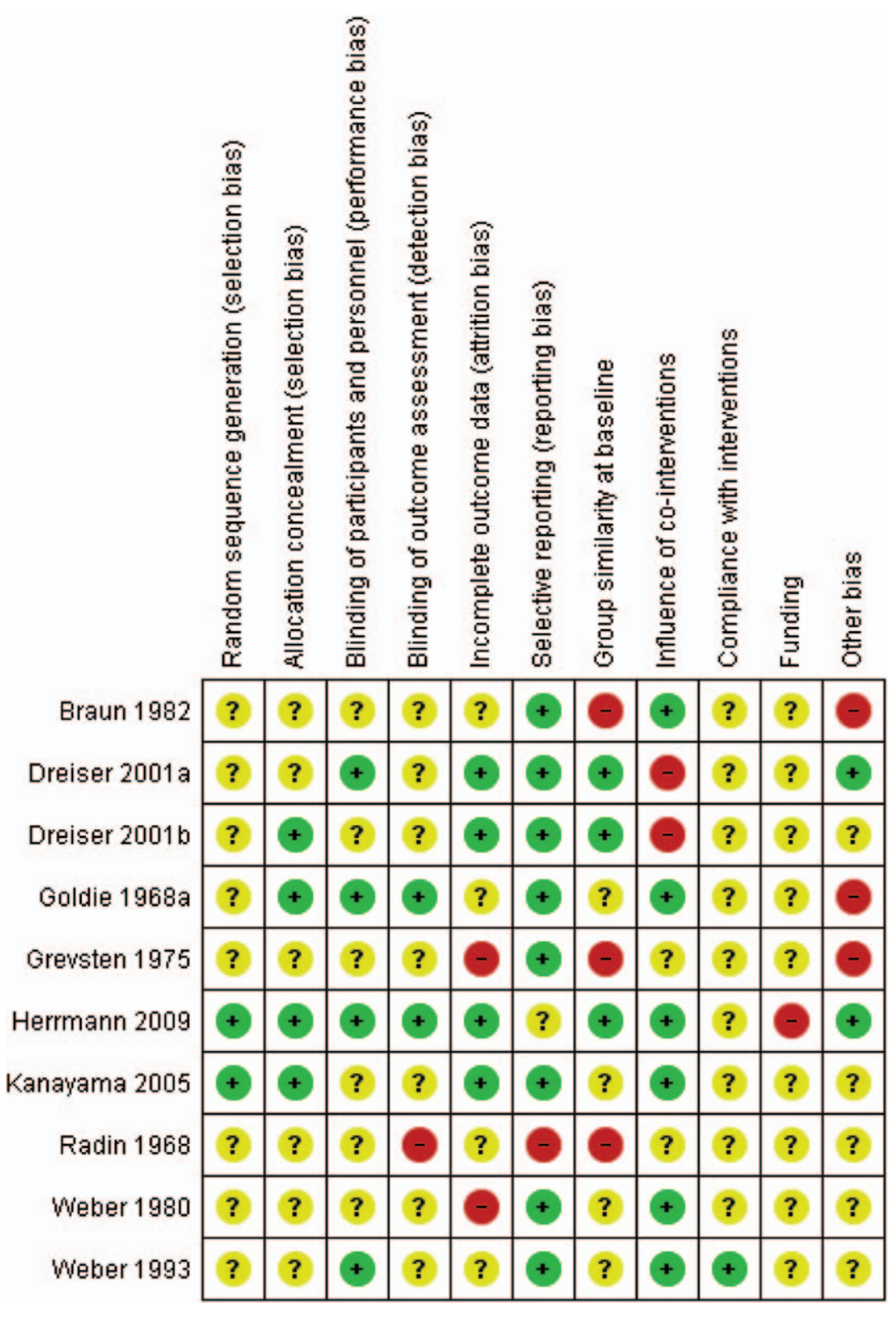

Figure 2. Risk of bias summary: review authors' judgements about each risk of bias item for each included study. followed by oral), whereas one trial ${ }^{28}$ compared diclofenac $(75 \mathrm{mg} /$ day $)$ with a serotonin or 5-hydroxytryptamine (5HT) inhibitor.

\section{Excluded Studies}

We excluded 27 studies during full-text review (Figure 1). The main reasons for exclusion were either that the participants were not suffering from sciatica or that the study design was not an RCT.

\section{Risk of Bias in Included Studies}

Risk of bias assessment is presented in Figure 2. One ${ }^{27}$ of the 10 trials fulfilled six or more criteria and was judged at low risk of bias. The other studies had selection bias, detection bias, and lack of clarity regarding compliance. All studies had either a high risk of bias or an unclear risk of bias regarding industry funding, compliance with the study medication, or small sample sizes.

\section{Effects of Interventions}

Change in Pain Intensity

NSAIDs Versus Placebo. Three trials (four treatment arms $)^{21,26,27}(\mathrm{~N}=918)$ reported on pain reduction (VAS) and were included in the meta-analysis (Figure 3). Dreiser et $a l^{21}$ found meloxicam $7.5 \mathrm{mg}$ superior to placebo, but $15 \mathrm{mg}$ did not increase the effect. We found very low-quality evidence that NSAIDs are no better than placebo (MD -4.56, $95 \% \mathrm{CI}-11.11$ to 1.99 , random-effects model, $I^{2}=82 \%$ ). When excluding one trial ${ }^{27}$ with a very short follow-up duration, the pooled MD was -0.09 (95\% CI -9.89 to $\left.9.71, I^{2}=86 \%\right)$. We downgraded the evidence two levels due to high risk of bias and one level due to inconsistency. NSAIDs Versus NSAID. Two trials ${ }^{21,27}$ compared the effect of two types of NSAIDs. There was no difference in mean pain reduction between lornoxicam ${ }^{27}$ and meloxicam (7.5/ $15 \mathrm{mg})^{21}$ compared with diclofenac. 


\begin{tabular}{|c|c|c|c|c|c|c|c|c|c|c|}
\hline \multirow[b]{2}{*}{ Study or Subgroup } & \multicolumn{3}{|c|}{ NSAID } & \multicolumn{3}{|c|}{ Placebo } & \multicolumn{3}{|c|}{ Mean Difference } & \multirow{2}{*}{$\begin{array}{c}\text { Mean Difference } \\
\text { IV, Random, } 95 \% \mathrm{Cl}\end{array}$} \\
\hline & Mean & SD & Total & Mean & SD & Total & Weight & IV, Random, $95 \% \mathrm{Cl}$ & Year & \\
\hline Weber 1993 & -11 & 19 & 120 & -16 & 21 & 94 & $25.2 \%$ & $5.00[-0.44,10.44]$ & 1993 & $F=$ \\
\hline Dreiser 2001a & -45 & 26.5 & 352 & -40 & 26.8 & 181 & $26.3 \%$ & $-5.00[-9.79,-0.21]$ & 2001 & -1 \\
\hline Herrmann 2009 & -22 & 13.5 & 57 & -13.7 & 13.4 & 29 & $24.3 \%$ & $-8.30[-14.31,-2.29]$ & 2009 & -- \\
\hline Herrmann 2009 & -24 & 13.5 & 57 & -13.7 & 13.4 & 28 & $24.2 \%$ & $-10.30[-16.38,-4.22]$ & 2009 & -- \\
\hline Total $(95 \% \mathrm{Cl})$ & & & 586 & & & 332 & $100.0 \%$ & $-4.56[-11.11,1.99]$ & & \\
\hline \multicolumn{10}{|c|}{$\begin{array}{l}\text { Heterogeneity: } \operatorname{Tau}^{2}=36.60 ; \mathrm{Chi}^{2}=16.76, \mathrm{df}=3(\mathrm{P}=0.0008) ; \mathrm{I}^{2}=82 \% \\
\text { Test for overall effect: } \mathrm{Z}=1.36(\mathrm{P}=0.17)\end{array}$} & $\begin{array}{ccccc}-50 & -25 & 0 & 25 & 50 \\
\text { Favours } & {[N S A I D]} & \text { Favours [Placeb }\end{array}$ \\
\hline
\end{tabular}

Figure 3. Forest plot of comparison: nonsteroidal anti-inflammatory drug (NSAID) versus placebo. Change in pain intensity summary.

NSAIDs Versus Other Drugs. Two trials ${ }^{20,28}$ compared NSAIDs with other drugs. Braun and Huberty ${ }^{20}$ compared ketoprofen intramuscular injection followed by oral ketaprofen with corticosteroids in addition to phenylbutazone intramuscular followed by oral corticosteroid in addition to phenylbutazone. Kanayama $e \mathrm{al}^{28}$ compared a serotonin or 5 -HT inhibitor with diclofenac $(75 \mathrm{mg} /$ day $)$. No difference in pain reduction was found between the treatments in either of the trials.

Change in Disability. Weber et $a^{26}(\mathrm{n}=214)$ compared NSAIDs (piroxicam) with placebo for change in functional outcomes $(\mathrm{RMDQ}=$ after 14 days and 4 weeks. There was very low-quality evidence that NSAIDs are no better than placebo, due to high risk of bias and imprecision.

\section{Global Improvement}

NSAID Versus Placebo. Five trials ${ }^{21,23,25-27}$ with a total of 846 participants reported on global improvement. We used three $21,26,27$ of the five trials $(\mathrm{N}=753)$ in the meta-anaysis as two trials ${ }^{23,25}$ used medications no longer on the market (phenylbutazone) (Figure 4). We found low-quality evidence that NSAIDs are more effective than placebo for global improvement (RR 1.14, 95\% CI 1.03 to 1.27; fixed-effect model, $\left.I^{2}=0 \%\right)$. The corresponding number needed to treat for an additional beneficial outcome (NNTB) was 12 participants based on the absolute risk difference of 0.09 (95\% CI 0.02 to 0.16 ). We downgraded the evidence two levels due to high risk of bias.

NSAID Versus NSAID. Two trials ${ }^{21,27}$ showed no difference in global improvement when lornoxicam and meloxicam were compared with diclofenac.
NSAID Versus Other Drugs. Two trials ${ }^{20,28}$ compared NSAIDs with other drugs. Ketoprofen intramuscular injection followed by ketoprofen oral compared with corticosteroids in addition to phenylbutazone intramuscular followed by oral corticosteroid in addition to phenylbutazone was comparable effective. ${ }^{20}$ No differences were found between serotonin or 5-HT inhibitor and diclofenac $(75 \mathrm{mg} / \mathrm{day}) .^{28}$

\section{Adverse Effects}

NSAID Versus placebo. The meta-analysis included four trials $^{21,22,26,27}(\mathrm{~N}=967)$, one with two treatment arms ${ }^{27}$ that used NSAIDs currently on the market (Figure 5). Two trials did not report adverse effects, ${ }^{20,28}$ whereas one trial ${ }^{25}$ found no adverse effects. The pooled analyses showed lowquality evidence for increased risk of adverse effects of NSAIDs compared with placebo (RR 1.40, 95\% CI 1.02 to 1.93$)$. When excluding one trial ${ }^{26}$ assessed with a high risk of bias the summary estimate was similar (RR 1.42, $95 \%$ CI 0.98 to 2.07$)$. The corresponding number needed to harm was 20 participants for one adverse effect based on an absolute risk difference of 0.05 (95\% CI 0.00 to 0.10$)$.

Most adverse effects were reported to be mild and comprised gastrointestinal problems described as nausea, dyspepsia, epigastric burning, abdominal pain, and in addition headache and dizziness. No perforation, ulceration, or bleeding of the upper gastrointestinal tract was reported. One life-threatening adverse event occurred: an anaphylactic shock requiring steroid therapy in the meloxicam $7.5 \mathrm{mg}$ group (treatment related), and there was one serious adverse event with deterioration of back

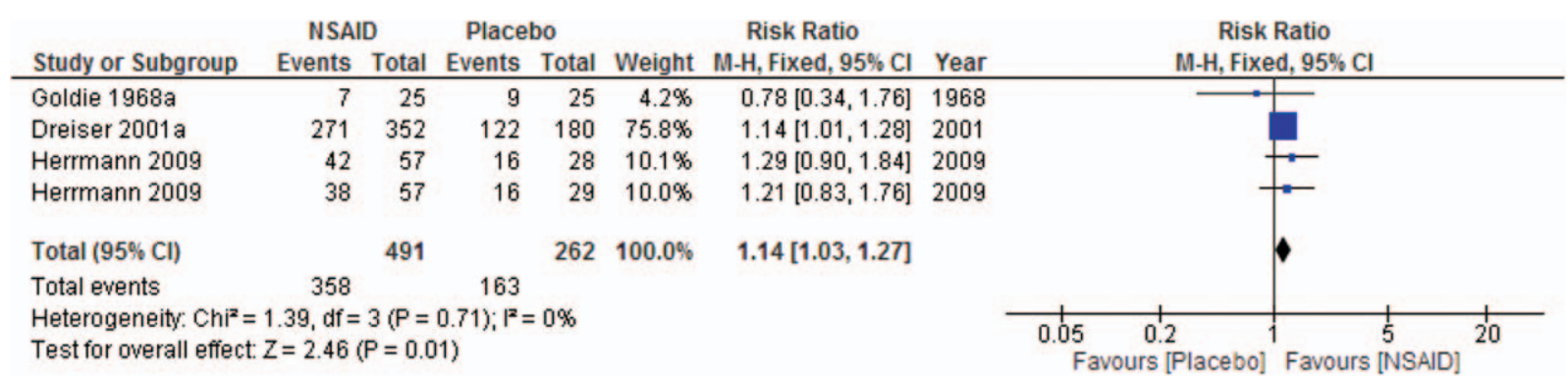

Figure 4. Forest plot of comparison: nonsteroidal anti-inflammatory drug (NSAID) versus placebo. Global improvement. 


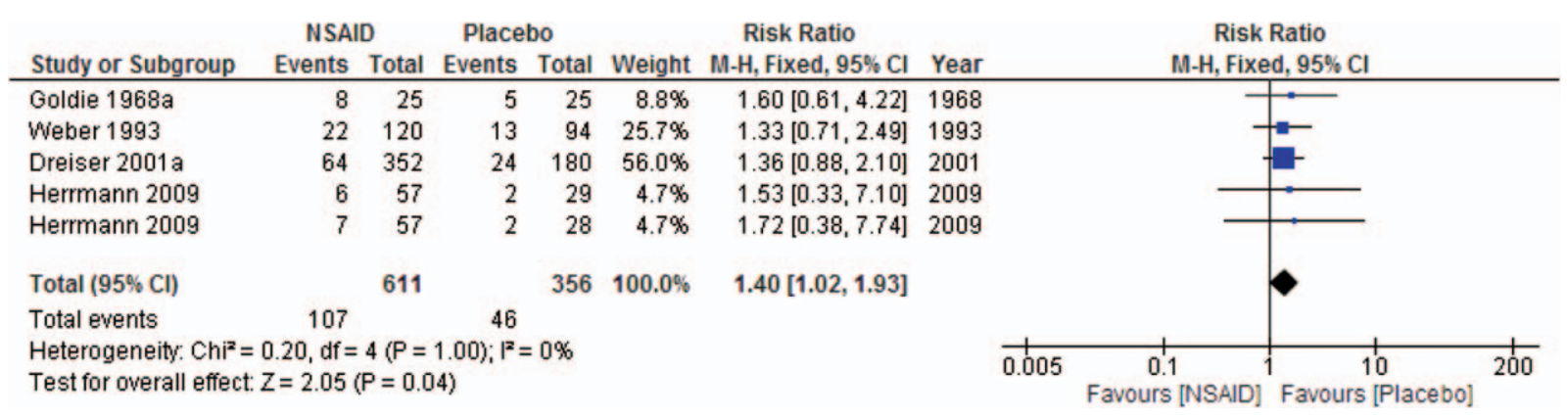

Figure 5. Forest plot of comparison: nonsteroidal anti-inflammatory drug (NSAID) versus placebo. Adverse effect summary.

pain in the placebo group (not treatment related). Both participants recovered.

NSAID Versus NSAID. Two trials ${ }^{21,27}$ comparing NSAIDs to NSAIDs reported no difference in adverse effects.

NSAID Versus Other Drugs. One trial ${ }^{20}$ did not report on adverse effects, whereas one trial ${ }^{28}$ reported no adverse effects.

Additional Use of Pain Medication. In participants treated with meloxicam $7.5 \mathrm{mg}$ less pain medications was used. ${ }^{21}$ An increase in the dose of meloxicam to $15 \mathrm{mg}$ did not decrease the need of additional pain medication. Two trials ${ }^{25,26}$ found no difference in the use of additional pain medication between NSAIDs and placebo and one $e^{20}$ no difference compared with other medication.

\section{DISCUSSION}

This updated Cochrane Review included 10 trials reported in nine publications. ${ }^{20-28}$ Only two additional trials ${ }^{27,28}$ were included compared with the original review. ${ }^{29}$ Given the high risk of bias in all trials but one, ${ }^{27}$ there is low to very low-quality evidence of the efficacy of NSAIDs compared with placebo or other drugs in the treatment of sciatica. Small study samples, incomplete outcome reporting, and inconsistency affected the grading of the quality of the evidence. Even if more participants with NSAIDs experienced global improvement compared with placebo, the grading of the evidence of the pooled analyses was low.

Recent reviews ${ }^{29-31}$ have included trials reporting on the efficacy of NSAIDs in acute and chronic LBP and with or without sciatica. Pinto et $a l^{30}$ included five of the trials included in our review, whereas excluding three $20,24,25$ due to unclear randomization and concluded that the graded evidence for the efficacy of NSAIDs is low due to limitations of study design and inconsistency. We chose to include and report on all trials even if assessed with a high risk of bias for full transparency on the efficacy of NSAIDs and sciatica. We, however, excluded two trials ${ }^{24,25}$ from the metaanalyses as these trials used NSAIDs no longer on the market. Furthermore, we excluded Weber et $a l^{26}$ due to high risk of bias to conduct a sensitivity analysis for the outcome of adverse effects. Even so, the finding of the sensitivity analysis did not change the results. In all, our findings are consistent with those of Pinto $e t a l^{30}$ for the effect of overall pain reduction. Furthermore, Wong et $a l^{31}$ concluded in a review that there was inconsistent evidence for the treatment of recent onset LBP with radiculopathy. Based on our thorough literature search, and other recently published reviews in the same area ${ }^{30,31}$ we find our evidence applicable. In addition, our results are in line with the original Cochrane Review ${ }^{29}$ on the efficacy of NSAIDs on sciatica.

Eight of the included trials reported on acute sciatica of less than 3 weeks' duration, whereas two ${ }^{24,25}$ provided no information on the duration. The external validity of our review thus only extends to those suffering from sciatica for less than 3 weeks. In addition, only one trial ${ }^{26}$ reported on the effect of NSAIDs on disability, ${ }^{26}$ with very low-quality evidence that NSAIDs are no more effective than placebo.

The risk for adverse effects of NSAIDs is well documented in the literature. ${ }^{32,33}$ All but two trials, ${ }^{20,28}$ reported on the risk of adverse effects for NSAIDs compared with placebo. Our finding of an increased risk for adverse effects was graded as low-quality evidence, and in addition the included trials did not have enough power to detect rare adverse effects. Thus, based on our findings we cannot draw any conclusion on the long-term effects of NSAIDs in sciatica. Although the GRADE quality of evidence was low due to the small study sample and a high risk of bias, the findings of risk for adverse effects in the present review are consistent with the literature. A recent guideline ${ }^{34}$ recommend the use of NSAIDs for sciatica with the lowest effective dose for the shortest possible period of time and to take adverse effects into account.

Our review expands the current evidence on the treatment efficacy of NSAIDs in sciatica with regard to several aspects. In addition to pain reduction, we assessed the effect on global improvement, finding that NSAIDs are more effective than placebo for sciatica. However, this finding must be treated with caution as some of the trials $^{27,28}$ allowed the use of additional pain medication and showed inconsistent results. In addition, although three trials ${ }^{20,25,26}$ found no difference between NSAIDs and placebo with regard to the use of additional pain medication, one trial ${ }^{21}$ found less use of pain medication in the NSAID group. ${ }^{28}$ 
The main limitations of the current review are the number of trials available, the high risk of bias, and the small sample size of included trials. Moreover, only four ${ }^{21,22,27,28}$ of the included publications reported on a power calculation. Another limitation is that we were not able to perform meta-analyses for all outcomes. For the outcome pain, heterogeneity of more than $80 \%$ between trials indicated that there was a wide range in treatment responses. As one study $\mathrm{arm}^{27}$ reported a short follow-up of eight hours we conducted a sensitivity analysis excluding the short-term arm, finding that the effect on pain reduction further decreased. To be able to detect if subgroups of participants with sciatica benefit from NSAIDs, additional analyses may be conducted which in the present review were not feasible due to insufficient trials and specific treatment responses. A further limitation is that only five trials assessed the treatment efficacy of currently available drugs in the recommended daily dose. ${ }^{20,21,26,27}$ Moreover, two trials used lower doses of NSAIDs (over the counter), which might explain less efficacy in those trials. 22,28

Due to the low number of included trials $(n=10)$ in the present review, we decided to include all eligible trials in the analyses even if assessed with a high risk of bias, using various doses, or reporting different short treatment outcome. We however conducted sensitivity analyses excluding trials with a high risk of bias. A limitation for the outcome of adverse effects is that for the individual studies there was clearly not enough power to detect rare adverse events, which means that we cannot fully exclude that potentially rare event may occur.

\section{CONCLUSION}

\section{Implications for Practice}

We found that NSAIDS are no more effective than placebo in short-term pain reduction (very low-quality evidence). NSAIDs are associated with more global improvement for sciatica at short-term follow-up (lowquality evidence). One trial assessed disability, and found no difference in effects between placebo and NSAIDs with very low-quality evidence. When prescribing NSAIDs in people with sciatica, the increased risk for adverse effects (low-quality evidence), also in short treatment duration, needs to be taken into account in the treatment decision.

\section{Implications for Research}

We found two additional trials for this updated review assessing the effect of NSAIDs compared to placebo or other drugs in sciatica, compared with the original review published in 2008. Most trials were assessed with a high risk of bias and included small study samples. For future studies on the efficacy of NSAIDs for sciatica, it might be important to investigate meta-regressions of defined subgroups of participants in methodologically sound RCTs.

\section{Key Points}

A systematic review assessed the efficacy of NSAIDs for sciatica.

口 Ten randomized trials were included $(N=1651)$. Only one had a low risk of bias.

- For pain relief in sciatica the literature does not support the use of NSAIDs as there is very low evidence that the efficacy of NSAIDs is comparable to placebo treatment for sciatica in pain relief.

- For global improvement there is low-quality evidence that NSAIDs are more effective than placebo.

- Adverse effects are more commonly reported when using NSAIDs compared to placebo with low-quality evidence.

The results of the review must be interpreted with caution due to the high risk of bias in the included trials and the overall low to very low-quality of the evidence.

Supplemental digital content is available for this article. Direct URL citations appearing in the printed text are provided in the HTML and PDF version of this article on the journal's Web site (www.spinejournal.com).

\section{References}

1. Hoy DG, Smith E, Cross M, et al. The global burden of musculoskeletal conditions for 2010: an overview of methods. Ann Rheum Dis 2014;73:982-9.

2. Vos T, Flaxman AD, Naghavi M, et al. Years lived with disability (YLDs) for 1160 sequelae of 289 diseases and injuries 1990-2010: a systematic analysis for the Global Burden of Disease Study 2010. Lancet 2012;380:2163-96.

3. Balague F, Mannion AF, Pellise F, et al. Non-specific low back pain. Lancet 2012;379:482-91.

4. Koes BW, van Tulder MW, Peul WC. Diagnosis and treatment of sciatica. BMJ 2007;334:1313-7.

5. Koes BW, van Tulder M, Lin CW, et al. An updated overview of clinical guidelines for the management of non-specific low back pain in primary care. Eur Spine J 2010;19:2075-94.

6. Valat JP, Genevay S, Marty M, et al. Sciatica. Best Pract Res Clin Rheumatol 2010;24:241-52.

7. Konstantinou K, Dunn KM. Sciatica: review of epidemiological studies and prevalence estimates. Spine (Phila $\mathrm{Pa}$ 1976) 2008;33:2464-72.

8. Konstantinou K, Hider SL, Jordan JL, et al. The impact of low backrelated leg pain on outcomes as compared with low back pain alone: a systematic review of the literature. Clin J Pain 2013;29:644-54.

9. Lewis R, Williams N, Matar HE, et al. The clinical effectiveness and cost-effectiveness of management strategies for sciatica: systematic review and economic model. Health Technol Assess 2011;15:1-578.

10. van Tulder M, Koes B. Low back pain and sciatica (chronic). Clin Evid 2003;10:1359-76.

11. Stafford MA, Peng P, Hill DA. Sciatica: a review of history, epidemiology, pathogenesis, and the role of epidural steroid injection in management. Br J Anaesth 2007;99:461-73.

12. Roelofs PD, Deyo RA, Koes BW, et al. Non-steroidal anti-inflammatory drugs for low back pain. Cochrane Database Syst Rev (1): 2008;CD000396. 
13. American Academy of Orthopaedic Surgeons (AOOS). What are NSAIDs? orthoinfo.aaos.org/topic.cfm?topic $=$ a00284 2009 (accessed July 1, 2016).

14. Dwivedi AK, Gurjar V, Kumar S, Singh N. Molecular basis for nonspecificity of nonsteroidal anti-inflammatory drugs (NSAIDs). Drug Discov Today 2015;7:863-73.

15. Brune K, Patrignani P. New insights into the use of currently available non-steroidal anti-inflammatory drugs. J Pain Res 2015;8:105-18.

16. Luijsterburg PA, Verhagen AP, Ostelo RW, et al. Effectiveness of conservative treatments for the lumbosacral radicular syndrome: a systematic review. Eur Spine J 2007;16:881-99.

17. Atkins D, Eccles M, Flottorp S, et al. Systems for grading the quality of evidence and the strength of recommendations I: critical appraisal of existing approaches The GRADE Working Group. BMC Health Serv Res 2004;4:38.

18. Higgins JPT, Green S. Cochrane Collaboration Cochrane Handbook for Systematic Reviews of Interventions 2011. www.cochrane-handbook.org (accessed October 20, 2015).

19. Furlan AD, Malmivaara A, Chou R, et al. 2015 Updated Method Guideline for Systematic Reviews in the Cochrane Back and Neck Group. Spine (Phila Pa 1976) 2015;40:1660-73.

20. Braun H, Huberty R. Therapy of lumbar sciatica. A comparative clinical study of a corticoid-free monosubstance and a corticoidcontaining combination drug. Die Medizinische Welt 1982;33: 490-1.

21. Dreiser RL, Le Parc JM, Velicitat P, et al. Oral meloxicam is effective in acute sciatica: two randomised, double-blind trials versus placebo or diclofenac. Inflamm Res 2001;50 (suppl 1):S17-23.

22. Goldie I. A clinical trial with indomethacin (indomee $(\mathrm{R}))$ in low back pain and sciatica. Acta Orthop Scand 1968;39:117-28.

23. Grevsten S, Johansson H. Phenylbutazone in treatment of acute lumbago-sciatica. Zeitschrift fur Rheumatologie 1975;34:444-7.

24. Radin EL, Bryan RS. Phenylbutazone for prolapsed discs? Lancet 1968;2:736-836.

25. Weber H, Aasand G. The effect of phenylbutazone on patients with acute lumbago-sciatica. A double blind trial. J Oslo City Hosp 1980;30:69-72.
26. Weber H, Holme I, Amlie E. The natural course of acute sciatica with nerve root symptoms in a double-blind placebo-controlled trial evaluating the effect of piroxicam. Spine (Phila Pa 1976) 1993;18:1433-8.

27. Herrmann WA, Geertsen MS. Efficacy and safety of lornoxicam compared with placebo and diclofenac in acute sciatical lumbo-sciatica: an analysis from a randomised, double-blind, multicentre, parallel-group study. Int J Clin Pract 2009;63: $1613-21$.

28. Kanayama M, Hashimoto T, Shigenobu K, et al. New treatment of lumbar disc herniation involving 5-hydroxytryptamine $2 \mathrm{~A}$ receptor inhibitor: a randomized controlled trial. J Neurosurg Spine 2005;2:441-6.

29. Roelofs PD, Deyo RA, Koes BW, et al. Non-steroidal anti-inflammatory drugs for low back pain. Cochrane Database Syst Rev 2008 / sb:host>CD000396. DOI: 10.1002/14651858.CD000396.pub3(1. DOI: $\quad 10.1002 / 14651858 . C D 000396 . p u b 3): C D 000396 . \quad$ DOI: 10.1002/14651858.CD000396.pub3.-CD000396. DOI: 10.1002/58. CD000396.pub3.

30. Pinto RZ, Maher CG, Ferreira ML, et al. Drugs for relief of pain in patients with sciatica: systematic review and meta-analysis. BMJ (Clin Res Ed) 2012;344:e497.

31. Wong JJ, Cote P, Ameis A, et al. Are non-steroidal anti-inflammatory drugs effective for the management of neck pain and associated disorders, whiplash-associated disorders, or nonspecific low back pain? A systematic review of systematic reviews by the Ontario Protocol for Traffic Injury Management (OPTIMa) Collaboration. Eur Spine J 2016;25:34-61.

32. Kowalski ML, Makowska JS. Seven steps to the diagnosis of NSAIDs hypersensitivity: how to apply a new classification in real practice? Allergy Asthma Immunol Res 2015;7:312-20.

33. Trelle S, Reichenbach S, Wandel S, et al. Cardiovascular safety of non-steroidal anti-inflammatory drugs: network meta-analysis. BMJ 2011;342:c7086.

34. NICE NIfHaCE. Low Back Pain and Sciatica in Over 16s: Assessment and Management, NICE Guideline NG59. National Guideline Centre; 2016. 